Original Research Paper

\title{
Graph Representation for Secondary System of Pressurized Water Reactor with Autocatalytic Set Approach
}

\author{
${ }^{1}$ Azmirul Ashaari, ${ }^{2}$ Tahir Ahmad, ${ }^{2}$ Mustaffa Shamsuddin, \\ ${ }^{1}$ Wan Munirah Wan Mohamad and ${ }^{1}$ Nazira Omar \\ ${ }^{I}$ Department of Mathematical Science, Faculty of Science, \\ Universiti Teknologi Malaysia, 81310 UTM, Skudai, Johor, Malaysia \\ ${ }^{2}$ Centre for Sustainable Nanomaterials, Ibnu Sina Institute for Scientific and Industrial Research, \\ Universiti Teknologi Malaysia, 81310 UTM, Skudai, Johor, Malaysia
}

Article history

Received: 20-04-2015

Revised: 07-09-2015

Accepted: 08-09-2015

Corresponding Author

Tahir Ahmad

Centre for Sustainable

Nanomaterials, Ibnu Sina

Institute for Scientific and

Industrial Research, Universiti

Teknologi Malaysia, 81310

UTM, Skudai, Johor, Malaysia

Email: tahir@ibnusina.utm

\begin{abstract}
The pace of nuclear reactor development in increasing and this is caused by the high authoritative ordinance of electricity from the end users. Furthermore, maintaining and controlling nuclear reactor operation are high priorities due to safety reasons. The aim of this paper is to describe the secondary system of Pressurized Water Reactor (PWR) system by using graph. Furthermore, fuzzy graph is used in performing a new graph based on its dynamicity. Finally, the results between crisp and fuzzy graph of the system are compared and verified against published data. The fuzzy graph of a secondary system of pressurized water reactor is better than a crisp graph of the system.
\end{abstract}

Keywords: Graph Theory, Nuclear Power Plant, Pressurized Water Reactor (PWR), Autocatalytic Set, Fuzzy Graph

\section{Introduction}

The Pressurized Water Reactor (PWR) contains two systems namely primary and secondary system as shown in Fig. 1. Nuclear fuel for PWR is Uranium dioxide (UO2) pellets located in the reactor core vessel of the primary system.

Most of the radioactive processes circulated within the primary system are caused by two separate systems of moderators circulating in steam generator.
The aim of this paper is to model the process which occurs in the secondary system of PWR.

The phase change from water to steam occurs in a steam generator. The steam is transferred to turbine in order to generate electricity. Next, phase change from steam to water or condensation process occurs in main condenser, which will later be transferred back into the steam generator. This process is repeated until the PWR reactor is shut down (USNRC, 2011).

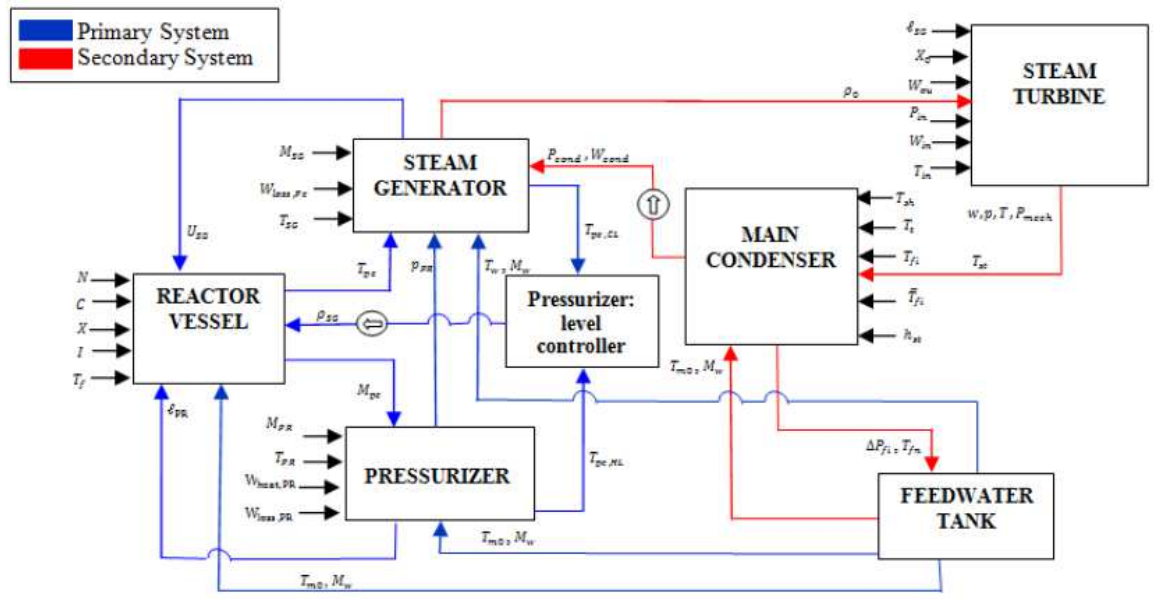

Fig. 1. Pressurizer Water Reactor (PWR) schemetic diagram system 


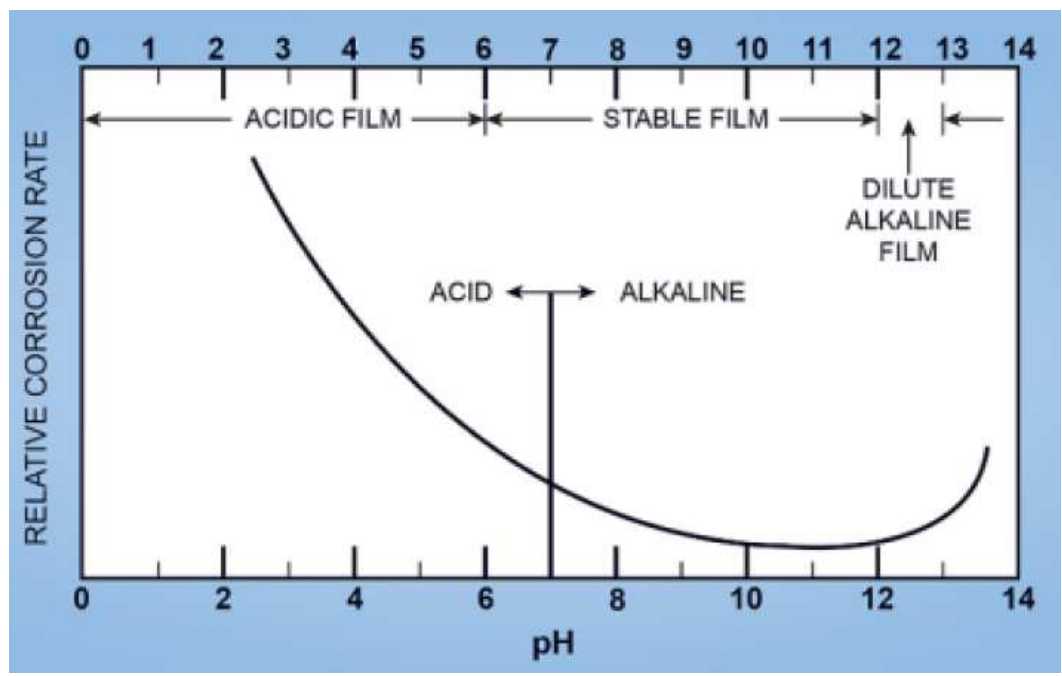

Fig. 2. Relationship between corrosion rate and $\mathrm{pH}$ for iron

Table 1. Incidents caused by corrosion

\begin{tabular}{lll}
\hline Plant & Year & Descriptions \\
\hline Oconee 3 & 1976 & Pinhole leak at extraction line \\
& 1980 & Thinned elbow caused by erosion/corrosion has been replaced \\
Browns ferry 1 & 1982 & Failure of 8-inch discharge line at the MSR drain pump \\
Oconee 2 & 1983 & Failure of a 3 to 10-inch expander downstream of a reheater drain tank \\
Calvert cliffs 1 & 1984 & Rupture of a 16-inch elbow in a branch line from a cold reheater steam line \\
Haddam neck & 1985 & Pipe rupture downstream of a feedwater heater \\
Kewaunee & 1985 & Rupture of a 2-inch excess steam vent line from a MSR \\
Hatch 2 & 1986 & Rupture of a 20 to 16-inch reducer in an extraction steam line \\
Ginna & 1986 & Failures of a 6-inch elbow of a moisture separator reheater drain line \\
\hline
\end{tabular}

Castelli (2009) presented the corrosion rate over time of PWR. In other work, Wu (1989) stated that erosion/corrosion is due to oxygen concentration and $\mathrm{pH}$ rate. Gedeon (1993) presented that corrosion occurs when there is acid or low $\mathrm{pH}$ rate. The relationship between corrosion rate and $\mathrm{pH}$ for Iron is shown in Fig. 2. Table 1 present various accidents which have occurred as a result of corrosion as stated in (Wu, 1989).

Kokaji (1995) stated that most nuclear power plants in Japan utilize a great amount of sea water for cooling condenser. Ibrahim et al. (2014; Ibrahim and Badawy, 2014) presented the impact of seawater salinity on the performance of the condenser. The increasing of sea water salinity leads to the decreasing of the heat-transfer coefficients in the condenser. Frepoli (2008) presented a sample result of a typical large break for Loss Of Coolant Accident (LOCA) analysis of PWR.

Most cases which occur in the secondary system are caused by the chemical of the compound mixture in the system. Hence, this paper describes the process and the dynamic of the secondary system via graph representation. The vertices and edge of a graph are used to represent the compounds and chemical reaction in the secondary system of PWR. Furthermore, the concept of graph is explained and described in the next section. The result for implementations, of Autocatalytic Set (ACS) and Fuzzy Autocatalytic Set (FACS) for secondary system of PWR is presented in the final section.

\section{Graph Theory}

Graph theory has been widely used in many areas such as in physics, chemistry, psychology, sociology and computer sciences (Balakrishnan and Ranganathan, 2012). Graph is defined as the networks of points or nodes that are connected by links (Balakrishnan and Ranganathan, 2012). A directed graph $\quad G=G(V$, $E$ ) is defined by a set $V$ of "nodes" and a set $E$ of "links" where each link is an ordered pair of nodes. The set of nodes and links can be represented as $V=\left\{v_{1}, v_{2}, v_{3}, \ldots v_{\mathrm{n}}\right\}$ and $E=\left\{e_{1}, e_{2}, v_{3}, \ldots v_{\mathrm{n}}\right\}$ with $C=\left(C_{i j}\right)$ is the adjacency matrix of a graph.

On the other hand, the concepts of fuzzy is used and implemented into graph theory after the evolution of fuzzy set theory introduced by (Zadeh, 1969). A fuzzy graph defined by Rosenfeid (2014) is presented as follows:

Definition 1: Fuzzy graph $\mathrm{G}=(\sigma, \mu)$ is a pair of functions $\sigma=S \rightarrow[0,1]$ and, $\sigma=S \times S \rightarrow[0,1], \forall x, y \in S$ where $\mu(x, y) \leq \sigma(x) \wedge \sigma(y)$. 


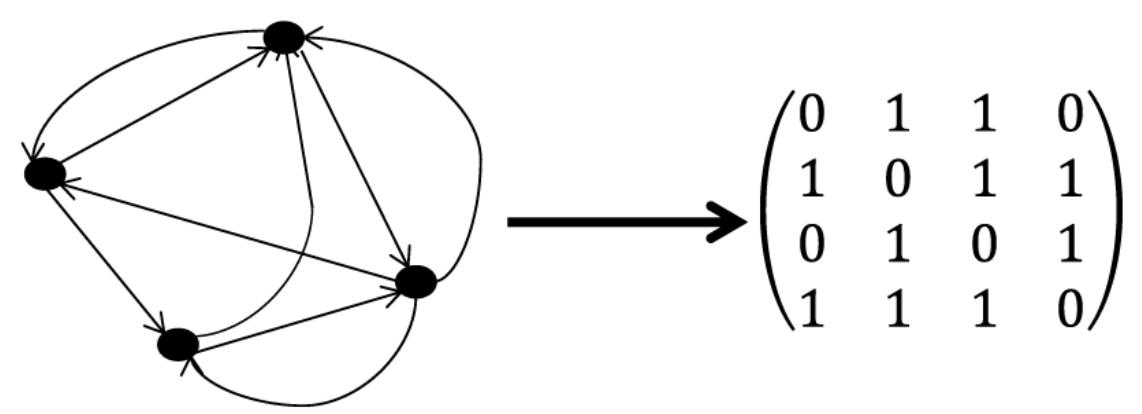

Fig. 3. A cycle, an Autocatalytic set (ACS) with 4 vertices

However, Tahir et al. (2009) introduced five types of fuzziness for graph based on the taxonomy of fuzzy graphs by Blue et al. (2002) as follows:

Definition 2: Fuzzy graph is a graph $G_{F}$ which satisfies one of the fuzziness ( $G_{F}^{i}$ of the $i^{\text {th }}$ type) or any of its combinations:

Type 1: $G_{F}^{1}=\left\{G_{1_{F}}, G_{2_{F}}, G_{3_{F}}, \ldots, G_{n_{F}}\right\}=\left\{V, E_{F}\right\}$ where fuzziness is on $G_{i_{F}}$ for $i=1,2,3, \ldots n$.

Type 2: $G_{F}^{2}=\left\{V, E_{F}\right\}$ where the edge set is fuzzy.

Type 3: $G_{F}^{3}\left\{V, E\left(t_{F}, h_{F}\right)\right\}$ where for the vertex and edge set are crispy, but the edge has fuzzy head and tail.

Type 4: $G_{F}^{4}\left\{V_{F}, E\right\}$ where the vertex set is fuzzy.

Type 5: $G_{F}^{5}\left\{V, E\left(w_{F}\right)\right\}$ where for the vertex and edge set are crispy, but the edge has fuzzy weights.

The term autocatalytic refers to a product or compound used to speed up a chemical reaction known as catalyst. Ostwald (1894a; 1894b; 1894) stated that catalysis is used to accelerate the slow chemical reaction with an addition of a foreign substance, but it is not consumed by the reaction. In general, an autocatalytic set is defined as a set of entities or a collection of entities where the word entities can be anything such as people, molecule or object. Further, the concept of an autocatalytic set was introduced in the context of interaction between compounds presented by Jain and Krishna (1998) formally as follows:

Definition 3: An Autocatalytic Set (ACS) is a sub graph, each of whose nodes have at least one incoming link from a node belonging to the same sub graph (Fig. 3).

An autocatalytic set can be presented in the form of matrix $n \times n$. An autocatalytic set of an incineration process was introduced by Tahir et al. (2009) as follows:

Definition 4: Fuzzy Autocatalytic Set (FACS) is a sub graph each of whose nodes have at least one incoming link with membership value $\mu\left(e_{i}\right) \in(0,1], \forall e_{i} \in E$.

These membership values are used in creating the adjacency matrix of a graph $\mathrm{C}$.

\section{An Autocatalytic Set of PWR System}

A set of vertices $V=\left\{v_{1}, v_{2}, v_{3}, v_{4}, v_{5}, v_{6}, v_{7}\right\}$ namely corrosion $\left(v_{1}\right)$, moderator $\left(v_{2}\right)$, sulphuric acid $\left(v_{3}\right)$, boric acid $\left(v_{4}\right)$, sodium hydroxide $\left(v_{5}\right)$, chlorides $\left(v_{6}\right)$ and nitrogen $\left(v_{7}\right)$ play an important role in presenting a secondary system of PWR as shown in Fig. 4. Castelli (2009) stated that the compounds of Co, $\mathrm{Zn}, \mathrm{Ni}, \mathrm{Fe}$ and $\mathrm{Zr}$ are classified as corrosion products. However, in this study the term corrosion is used rather than corrosion products. The seven edges of $\mathrm{E}$ represent the links of vertices are shown in Table 2.

\section{Fuzzy Autocatalytic Set of PWR System}

The introduction of fuzziness into an autocatalytic set of fuzzy graph type 3 was given by Tahir et al. (2009):

Definition 5: Let $e_{1} \in E$. The fuzzy head of $e_{i}$ is denoted as $h\left(e_{i}\right)$ and the fuzzy tail $t\left(e_{i}\right)$ is a function of $e_{i}$ such that $h: E \rightarrow[0,1]$ and $t: E \rightarrow[0,1]$ for $e_{i} \in E$. A fuzzy edge connectivity is a tuple $\left(t\left(e_{i}\right), h\left(e_{i}\right)\right)$ and the set of all fuzzy edge connectivity is denoted as $C=\left\{\left(t\left(e_{i}\right), h\left(e_{i}\right)\right): e_{i} \in E\right\}$.

The value for $t\left(e_{i}\right)$ is equal to 1 since reaction with other variables is taken place. However, the value for $h\left(e_{i}\right)$ is taken in the interval of $(0,1]$ due to the strength of connection or reaction with another variable. Therefore the membership value for fuzzy edge is defined as follows:

$\mu\left(e_{i}\right)=\min \left\{t\left(e_{i}\right), h\left(e_{i}\right)\right\}$

The data for our models is taken from AP1000 nuclear power plant (Winters et al., 2009a). The crisp graph $G_{s}$ shows that each link has the same color and thickness due to the same value of connectivity between the vertices in the graph (Fig. 4(a)). However, the fuzzy graph $G_{S_{F}}$ provided different membership value. The different colour of links signifies the distinct range of membership value where the greater value of connectivity is indicated by thickness of edges (Fig. 4(b)). 


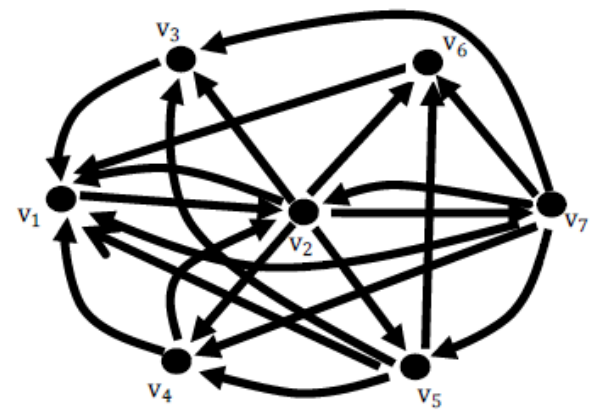

(a)

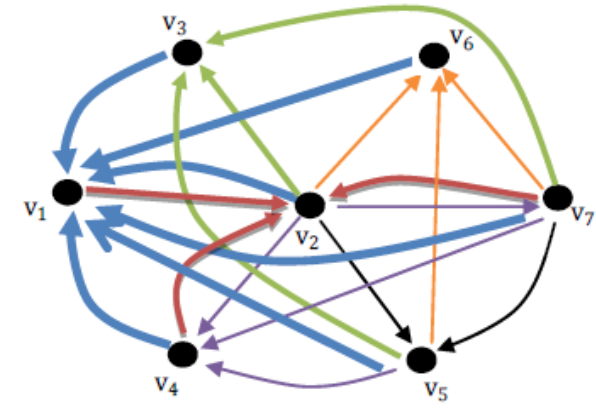

(b)

Fig. 4. Graph secondary system of PWR: (a) crisp graph, $G_{S}$ (b) Fuzzy graph, $G_{s_{F}}$

Table 2. Edge descriptions for graph $G_{S}$ of secondary system PWR

\begin{tabular}{|c|c|}
\hline Vertices & Descriptions \\
\hline$\left(v_{3}, v_{1}\right)$ & $\begin{array}{l}\text { Corrosion occurred in the presence of acid. Iron is dissolved by sulphuric acid to form } \mathrm{FeSO}_{4} \text { (Gedeon, 1993) } \\
\mathrm{Fe}+\mathrm{H}_{2} \mathrm{SO}_{4} \rightarrow \mathrm{FeSO}_{4}+\mathrm{H}_{2}\end{array}$ \\
\hline$\left(v_{6}, v_{1}\right)$ & The chemical reaction between chlorine and iron to form $\mathrm{FeCl}_{3}$ as stated in (Castelli, 2009) \\
\hline$\left(v_{2}, v_{1}\right)$ & The oxygen in moderator $\left(\mathrm{H}_{2} \mathrm{O}\right)$ is one of the causes of corrosion $(\mathrm{Wu}, 1989)$ \\
\hline$\left(v_{1}, v_{2}\right)$ & $\begin{array}{l}\text { Ferrous oxide that is highly soluble in an acidic solution is the corrosion product. Gedeon (1993) stated that } \\
\text { moderator is formed in the presence of hydrogen and ferrous oxide }\end{array}$ \\
\hline$\left(v_{7}, v_{1}\right)$ & $\begin{array}{l}\text { Nitric acid }\left(\mathrm{HNO}_{3}\right) \text { is formed by chemical reaction between moderator and nitrogen dioxide. Low } \mathrm{pH} \text { is a corrosion } \\
\text { factor (Gedeon, 1993) }\end{array}$ \\
\hline$\left(v_{4}, v_{1}\right)$ & $\begin{array}{l}\text { Boric acid } \mathrm{B}(\mathrm{OH})_{3} \text { is an acidic compound and one of the factors for corrosion occurrence as stated in } \\
\text { (Gedeon, 1993) }\end{array}$ \\
\hline$\left(v_{5}, v_{4}\right)$ & The chemical reaction between sodium hydroxide and boric acid formed sodium borate $\left(\mathrm{Na}_{2} \mathrm{~B}_{4} \mathrm{O}_{7}\right)$ \\
\hline$\left(v_{5}, v_{3}\right)$ & The chemical reaction between acid sulphuric with sodium hydroxide formed sodium sulphate $\left(\mathrm{Na}_{2} \mathrm{SO}_{4}\right)$ \\
\hline$\left(v_{2}, v_{3}\right)$ & The sulfuric acid compound is the products of sulfur trioxide $\left(\mathrm{SO}_{3}\right)$ infused with the moderator $(\mathrm{Lin}, 1996)$ \\
\hline$\left(v_{4}, v_{2}\right)$ & Boric acid heated above $170{ }^{\circ} \mathrm{C}$ forms moderator compound as stated in (Lin, 1996) \\
\hline$\left(v_{2}, v_{4}\right)$ & When diborane $\left(\mathrm{B}_{2} \mathrm{H}_{6}\right)$ is infused with the moderator, the boric acid compound is crystallized (Lin, 1996) \\
\hline$\left(v_{7}, v_{4}\right)$ & The chemical reaction between ammonia and boric acid formed Boron Nitride (BN) \\
\hline$\left(v_{2} v_{6}\right)$ & Chloride compound is formed based on chemical reaction between hydrochloric acid $(\mathrm{HCl})$ with hydroxide $\left(\mathrm{OH}^{-}\right)$ \\
\hline$\left(v_{2}, v_{5}\right)$ & The chemical reactions between moderator and sodium $(\mathrm{Na})$ produced sodium hydroxide $(\mathrm{NaOH})$ compound \\
\hline$\left(v_{5}, v_{6}\right)$ & $\begin{array}{l}\text { Sodium Chloride }(\mathrm{NaCl}) \text { compound is formed based on chemical reaction between sodium hydroxide with } \\
\text { hydrochloride acid ( } \mathrm{Lin}, 1996)\end{array}$ \\
\hline$\left(v_{7}, v_{6}\right)$ & Ammonia compound reacted with hydrochloride acid forming ammonium chloride $\left(\mathrm{NH}_{4} \mathrm{Cl}\right)$ \\
\hline$\left(v_{7}, v_{3}\right)$ & The reaction of a sulphuric acid with base ammonia showed that salt $\left(\mathrm{NH}_{4}\right)_{2} \mathrm{SO}_{4}$ is formed $(\mathrm{Lin}, 1996)$ \\
\hline$\left(v_{7}, v_{2}\right)$ & $\begin{array}{l}\text { Nitrogen is used to control } \mathrm{pH} \text { in the moderator. The chemical reaction between nitrogen with } \\
\text { moderator occurs as stated in (Gedeon, 1993) }\end{array}$ \\
\hline$\left(v_{2}, v_{7}\right)$ & The chemical reaction between nitrogen and hydrogen forms $\mathrm{NH}_{3}$ (Gedeon, 1993); i.e., $3 \mathrm{H}_{2}+\mathrm{N}_{2} \rightleftarrows 2 \mathrm{NH}_{3}$ \\
\hline$\left(v_{7}, v_{5}\right)$ & The chemical reaction between with form sodium nitrate $\left(\mathrm{NaNO}_{3}\right)$. \\
\hline$\left(v_{5}, v_{1}\right)$ & $\begin{array}{l}\text { The excess sodium are caused caustic Stress Corrosion Cracking (SCC) to the equipment in secondary system } \\
\text { (Winters et al., 2009b) }\end{array}$ \\
\hline
\end{tabular}

\section{Results and Discussion}

The dynamic model proposed in (Sabariah et al., 2002) is used to model secondary system of PWR. The concentration dynamics of the initial phase for crisp graph and fuzzy graph are given in the following Table 3. The rate of change for corrosion is a positive value for fuzzy graph compared to a negative value for crisp graph. The corrosion value should be positive since the PWR nuclear reactor had been in operation for more than one year before shutting down, which caused the corrosion values to increase.
However, the rate of change for $\mathrm{NaOH}, \mathrm{Cl}_{2}$ and $\mathrm{N}_{2}$ are negative for fuzzy graph compared to positive values for crisp graph. The concentration of $\mathrm{NaOH}, \mathrm{Cl}_{2}$ and $\mathrm{N}_{2}$ should have been decreased since it was being consumed during the process. Furthermore, the rate of change values obtained for $\mathrm{B}(\mathrm{OH})_{3}$ from fuzzy graph is less than crisp graph. This is reasonable since the amount of boric acid in the diluted moderator is small (Winters et al., 2009a). Table 4 shows the comparison sequence of depletion variables and the variables that remained for crisp graph and fuzzy graph $G_{S}$ for the PWR system. 
Table 3. Concentration dynamics for crisp graph and fuzzy graph

\begin{tabular}{|c|c|c|c|}
\hline Vertices & Variable & Rate of change for crisp graph $G_{S}$ & Rate of change for fuzzy graph $G_{S_{F}}$ \\
\hline$V_{1}$ & Corrosion (Co, Zn, Ni, Fe, Zr) & -0.0704 & 0.1884 \\
\hline$V_{2}$ & $\mathrm{H}_{2} \mathrm{O}$ & -0.3027 & -0.0599 \\
\hline$V_{3}$ & $\mathrm{H}_{2} \mathrm{SO}_{4}$ & -0.2821 & -0.0699 \\
\hline$V_{4}$ & $\mathrm{~B}(\mathrm{OH})_{3}$ & 0.3323 & 0.0127 \\
\hline$V_{5}$ & $\mathrm{NaOH}$ & 0.2991 & -0.0043 \\
\hline$V_{6}$ & $\mathrm{Cl}_{2}$ & 0.0136 & -0.0373 \\
\hline$V_{7}$ & $\mathrm{~N}_{2}$ & 0.0100 & -0.0297 \\
\hline
\end{tabular}

Table 4. Sequence of depletion variables for crisp and fuzzy graph

\begin{tabular}{lll}
\hline & Crisp graph $G_{S}$ & Fuzzy graph $G_{S_{F}}$ \\
\hline Sequence of & $\mathrm{N}_{2}, \mathrm{NaOH}$, & $\mathrm{NaOH}_{2} \mathrm{~B}(\mathrm{OH})_{3}$, \\
variables that & $\mathrm{Cl}_{2} \mathrm{~B}(\mathrm{OH})_{3}$, & $\mathrm{Cl}_{2}, \mathrm{~N}_{2}, \mathrm{H}_{2} \mathrm{SO}_{4}$ \\
are depleted & $\mathrm{H}_{2} \mathrm{SO}_{4}$ & \\
Variables that & $\mathrm{H}_{2} \mathrm{O}$ and & $\mathrm{H}_{2} \mathrm{O}$ and \\
left when system & Corrosion $(\mathrm{Co}$, & Corrosion $(\mathrm{Co}$, \\
is shut down & $\mathrm{Zn}, \mathrm{Ni}, \mathrm{Fe}, \mathrm{Zr})$ & $\mathrm{Zn}, \mathrm{Ni}, \mathrm{Fe}, \mathrm{Zr})$ \\
\hline
\end{tabular}

The sequences of depletion for fuzzy graph $G_{S_{F}}$ are more justifiable than the crisp graph $G_{S}$ since $N_{2}$ should not be depleted as early since there is more $\mathrm{N}_{2}$ in the secondary system than $\mathrm{NaOH}$. Moreover, $\mathrm{B}(\mathrm{OH})_{3}$ is depleted earlier than $\mathrm{Cl}_{2}$ since the quantity of boric acid is less than chlorides. However, variables that survived at the end of the operation for both graphs are the same. The corrosion's product and moderators exist till the end of the operation, which confirmed by Murray (2009).

\section{Conclusion}

Graph representation of Autocatalytic Set for secondary system of Pressurizer Water Reactor is successfully presented. The procedure and the development of crisp and fuzzy graph are described in the paper. Moreover, the results from fuzzy graph show that the concentration dynamics and the sequence of depletion variables are better than crisp graph.

\section{Acknowledgement}

This work has been supported by Ibnu Sina Institute, MyBrain15 scholarship from Ministry of Education Malaysia and Universiti Teknologi Malaysia.

\section{Author's Contributions}

Azmirul Ashaari and Tahir Ahmad: Contributed in developing the graph of secondary system of PWR.

Mustaffa Shamsuddin: Confirmed the chemical reaction equations.

Wan Munirah Wan Mohamad and Nazira Omar: Provided the literature reviews.

\section{Ethics}

The authors declare that there is no conflict of interests regarding the publication of this article.

\section{References}

Frepoli, C., 2008. An overview of westinghouse realistic large break LOCA evaluation model. Sci. Technol. Nuclear Installations, 2008: 1-15.

DOI: $10.1155 / 2008 / 498737$

Tahir, A., B. Sabariah and K.A. Arshad, 2009. Modeling a clinical incineration process using fuzzy autocatalytic set. J. Chemistry.

Lin, C.C., 1996. Radiochemistry in Nuclear Power Reactors. 1st Edn., National Academies Press, Washington, DC.

Ibrahim, M. and M.R. Badawy, 2014. A parametric study of the impact of the cooling water site specific conditions on the efficiency of a pressurized water reactor nuclear power plant. Int. J. Nuclear Energy, 2014: 1-6. DOI: $10.1155 / 2014 / 569658$

Ibrahim, S.M.A. and M.M.A. Ibrahim and S.I. Attia, 2014. The impact of climate changes on the thermal performance of a proposed pressurized water reactor: nuclear-power plant. Int. J. Nuclear Energy, 2014: 1-7. DOI: $10.1155 / 2014 / 793908$

Kokaji, I., 1995. The present status for thermal discharge of nuclear power plant. Progress Nuclear Energy, 29: 413-420. DOI: 10.1016/0149-1970(95)00070-Z

Rosenfeid, A., 2014. Fuzzy Graphs'I'. In: Fuzzy Sets and Their Applications to Cognitive and Decision Processes, Academic Press, University of California, Berkeley, pp: 77-77.

Blue, M., B. Bush and J. Puckett, 2002. Unified approach to fuzzy graph problems. Fuzzy Set Syst., 125: 355-368. DOI: 10.1016/S0165-0114(01)00011-2

Wu, P.C., 1989. Erosion/corrosion-induced pipe wall thinning in US nuclear power plants. Nuclear Regulatory Commission, Div. of Engineering and Systems Technology, Washington, DC.

Gedeon, P.G., 1993. Fundamentals of chemistry, nuclear engineering and technology. Continuing Education and Development, Inc. 
Murray, R.L., 2009. Nuclear Energy: An Introduction to the Concepts, Systems and Applications of Nuclear Processes. 6th Edn., Elsevier Inc., UK, ISBN-10: 978-0-12-370547-1, pp: 17.

Balakrishnan, R. and K. Ranganathan, 2012. A Textbook of Graph Theory. 1st Edn., Springer Science and Business Media, New York, ISBN-10: 1461445280, pp: 292.

Castelli, R., 2009. Nuclear Corrosion Modeling: The Nature of CRUD. 1st Edn., Butterworth-Heinemann, Amsterdam, ISBN-10: 1856179346, pp: 216.

Jain, S. and S. Krishna, 1998. Autocatalytic sets and the growth of complexity in an evolutionary model. Phys. Rev. Lett., 81: 5684-5687.

DOI: 10.1103/PhysRevLett.81.5684

Winters, J.W., R.P. Vijuk and W.E. Cummins, 2009a. UK AP1000 D1 form submission UKP-GW-GL-058. Westinghouse Electric Company LLC, Pittsburgh.

Winters, J.W., R.P. Vijuk and W.E. Cummins, 2009b. AP1000 European design control document EPSGW-GL-700 Rev 1. Westinghouse Electric Company LLC, Pittsburgh.
USNRC, 2011. Pressurized Water Reactor (PWR) systems. In manual, reactor concepts water, pressurized systems, reactor.

Ostwald, W., 1894a. Definition der katalyse. Zeitschrift für Physikalische Chemie, 15: 705-706.

Ostwald, W., 1894b. Über katalyse. Annalen der Naturphilosophie, 9: 1-25.

Ostwald, W., 1894c. Über katalyse. Physikalische Zeitschrift, 3: 313-322.

Zadeh, L.A., 1969. Fuzzy sets. Inform. Control, 8: 338-353. DOI: 10.1016/S0019-9958(65)90241-X

Sabariah, B., T. Ahmad and A.A. Khairil, 2002. Graphical presentation of a clinical waste incinerations proses. Proceedings of the 10th National Symposium of Mathematical Sciences, (SMS’ 02), Johor Bahru. 